\title{
Is Green Growth Possible?
}

\author{
Jason Hickel ${ }^{a}$ and Giorgos Kallis ${ }^{b}$ \\ a Anthropology, Goldsmiths, University of London, London, UK; \\ ${ }^{b}$ ICREA and ICTA-UAB, Universitat Autonoma de Barcelona, Barcelona, Spain
}

\section{Keywords}

Sustainable development, ecological economics, green growth, degrowth, decoupling

\begin{abstract}
The notion of green growth has emerged as a dominant policy response to climate change and ecological breakdown. Green growth theory asserts that continued economic expansion is compatible with our planet's ecology, as technological change and substitution will allow us to absolutely decouple GDP growth from resource use and carbon emissions. This claim is now assumed in national and international policy, including in the Sustainable Development Goals. But empirical evidence on resource use and carbon emissions does not support green growth theory. Examining relevant studies on historical trends and model-based projections, we find that: (1) there is no empirical evidence that absolute decoupling from resource use can be achieved on a global scale against a background of continued economic growth, and (2) absolute decoupling from carbon emissions is highly unlikely to be achieved at a rate rapid enough to prevent global warming over $1.5 \mathrm{C}$ or $2 \mathrm{C}$, even under optimistic policy conditions. We conclude that green growth is likely to be a misguided objective, and that policymakers need to look toward alternative strategies.
\end{abstract}

\section{Introduction}

The notion of green growth emerged as a central theme at the Rio+20 Conference on Sustainable Development in 2012, and featured prominently in the outcome document The World We Want (UN 2012), which called simultaneously for a 'green economy' and 'sustained economic growth'. Green growth has since become a dominant response to increasingly serious warnings about climate change and ecological breakdown (Dale et al. 2016). As a theory, green growth asserts that continued economic expansion (as measured by Gross Domestic Product, or GDP) is or can be made to be compatible with our planet's ecology. While this idea has been latent in the rhetoric of sustainable development since the Brundtland Commission and the first Rio Conference, with early formulations taking shape under names like Ecological Modernization (Ayres et al 1993, 
Weizsacker et al. 1998) or the Environmental Kuznets curve hypothesis (Dasgupta et al. 2002), green growth theory renders it as a formal assertion.

Green growth theory is now promoted by leading multilateral organizations and is assumed in national and international policy. It rests on the assumption that absolute decoupling of GDP growth from resource use and carbon emissions is feasible (e.g., Solow 1973), and at a rate sufficient to prevent dangerous climate change and other dimensions of ecological breakdown. This review paper examines this assumption, and tests it against extant empirical evidence. We ask: how do international organizations define green growth? Does the theory of green growth (and specifically, the assumption that absolute decoupling of GDP growth from material throughput and carbon emissions can be accomplished at a sufficiently rapid rate) withstand scrutiny in light of existing data and model-based projections? And if not, what are the implications for policy?

\section{Defining green growth}

There are three major institutional proponents of green growth theory at the international level: the OECD, the United Nations Environment Program (UNEP), and the World Bank. Each published flagship reports on green growth around the time of the Rio+20 Conference. In 2011, the OECD launched a green growth strategy titled Towards Green Growth. That same year, UNEP published a report titled Toward a Green Economy: Pathways to Sustainable Development and Poverty Eradication. In 2012, the World Bank published Inclusive Green Growth: The Pathway to Sustainable Development. During the Rio+20 Conference, these institutions joined with the Global Green Growth Institute to create the Green Growth Knowledge Platform as an instrument for advancing green growth strategy around the world.

Each of the three organizations offers a different definition of green growth. The OECD defines it as 'fostering economic growth and development while ensuring that natural assets continue to provide the resources and environmental services on which our well-being relies' (2011, p. 18). The World Bank (2012) defines it as 'economic growth that is efficient in its use of natural resources, clean in that it minimizes pollution and environmental impacts, and resilient in that it accounts for natural hazards and the role of environmental management and natural capital in preventing physical disasters.' UNEP eschews the language of green growth in favor of 'green economy', which it defines as one that simultaneously grows income and improves human wellbeing 'while significantly reducing environmental risks and ecological scarcities' (2011b: 16).

None of these definitions are as precise as we might hope (see Jacobs 2013). As Smulders (2014) points out, the concept of green growth is 'new and still somewhat amorphous.' The World Bank's definition is the weakest. The World Bank seeks to 'minimize' the environmental impact of growth; but one can minimise the environmental impact without reducing impact from its present levels, and indeed while still nonetheless increasing overall impact. The OECD is slightly stronger in that it seeks to 'maintain' resources and environmental services, but here too there is no demand to reduce impact. The UNEP report offers the strongest definition in that it calls for reducing environmental impact and ecological scarcities, and for rebuilding natural capital.

The three institutions agree however on the mechanism for achieving green growth. The promise is that technological change and substitution will improve the ecological efficiency of the economy, and that governments can speed this process with the right regulations and incentives. 
But they differ in the clarity of their claims. The World Bank does not ask whether policy-driven innovations will suffice to reduce environmental impact. The OECD, for its part, clarifies that green growth is only possible if technology becomes efficient enough to achieve 'decoupling' of growth from environmental impact. UNEP takes this a step further, and puts decoupling at the center of the analysis: 'A key concept for framing the challenges we face in making the transition to a more resource efficient economy is decoupling. As global economic growth bumps into planetary boundaries, decoupling the creation of economic value from natural resource use and environmental impacts becomes more urgent.' UNEP notes that 'recent trends indicate a moderate tendency of relative decoupling over time', but points out that this is not enough: 'The central challenge... is to decouple growth absolutely from material and energy intensity' (UNEP 2011b, p. 15).

Here again UNEP offers the clearest - and strongest - policy-oriented definition of green growth, namely, that green growth requires absolute decoupling of GDP from resource use and environmental impact. This is in keeping with the ecological literature, which insists that in a context of ecological overshoot (Rockstrom et al. 2009, Steffen et al. 2015, Ceballos et al. 2015, Ceballos et al. 2017), it is not enough to simply 'minimize' environmental impact - we must rapidly reduce it down to safe limits.

This leaves us with the question: Is absolute decoupling possible, and, if so, is it possible at a rate sufficient for returning to and staying within planetary boundaries? None of the three reports on green growth provide any evidence that it is. But since the Rio+20 conference, a number of key studies have emerged to shed new light on this question. We outline the findings of this empirical literature in what follows, looking at the two primary dimensions of decoupling - resource use and carbon emissions - in turn, ${ }^{1}$ before discussing theoretical and policy implications.

\section{Resource use - is absolute decoupling possible?}

The conventional metric for measuring an economy's resource use is 'domestic material consumption' (DMC), which is the total weight of raw materials (biomass, minerals, metals and fossil fuels) extracted from the domestic territory, plus all physical imports minus all physical exports. While DMC is not a direct indicator of ecological pressure, it is a well-established and widely-used proxy in the policy literature and enjoys robust empirical grounding for this purpose (Krausmann et al. 2009, p. 2703). Van der Voet et al $(2004,2005)$ find that while the mass flows of individual materials are not indicative of their ecological impacts, and while impacts vary as technologies change, at an aggregate level there is a high degree of correlation (0.73) between material throughput and ecological impacts.

To assess the relationship between GDP and resource use, many governments have adopted the practice of dividing GDP by DMC. This gives an indication of the 'resource efficiency' of an economy. If GDP grows faster than DMC (relative decoupling), the economy is becoming more resource efficient. GDP/DMC is used by the European Union to monitor progress toward green growth. It is also the headline metric of the OECD's annual Green Growth Indicators report.

By this metric, it appears that many nations have achieved relative decoupling, with GDP growing at a rate faster than DMC. In the 2017 edition of Green Growth Indicators, the OECD concluded that 'material productivity has been improving in some OECD countries' (45). The report also indicates that European OECD nations have achieved absolute decoupling, growing GDP while reducing DMC. Non-energy material consumption in the OECD declined from 12 tonnes per capita in 2000 to 10 tonnes per capita in 2015, with the downward trend beginning after 
the financial crisis in 2008 (it should be noted, however, that the OECD's version of DMC does not include fossil fuels; this is not normal practice in the literature on material flows). These data are key to optimistic green growth narratives, and underpin the popular notion that we have reached 'peak stuff' (e.g., Pearce 2011, Goodall 2011).

DMC is a problematic indicator, however, as it does not include the material impact involved in the production and transport of imported goods (Wiedmann et al. 2015, Gutowski et al. 2017). In a globalised economy, where rich countries have outsourced much of their production to poorer countries, this side of material consumption has been shifted off their balance sheet. If we bring it back in, looking at the total resource impact of consumption by any given nation (what Wiedmann et al refer to as 'material footprint', or MF), the picture changes. Wiedmann et al show that while the USA, UK, Japan, the OECD and EU-27 have achieved relative decoupling of GDP from DMC (including fossil fuels), material footprint has been rising at a rate equal to or greater than GDP, suggesting no decoupling at all; indeed, in most cases re-coupling has occurred (see Figure 1). The Green Growth Indicators partly recognises this problem, stating 'progress is moderate once indirect flows associated with trade are considered.' Yet the report does not provide any data on indirect flows; and the data that is available suggests that progress has been not moderate but negative.
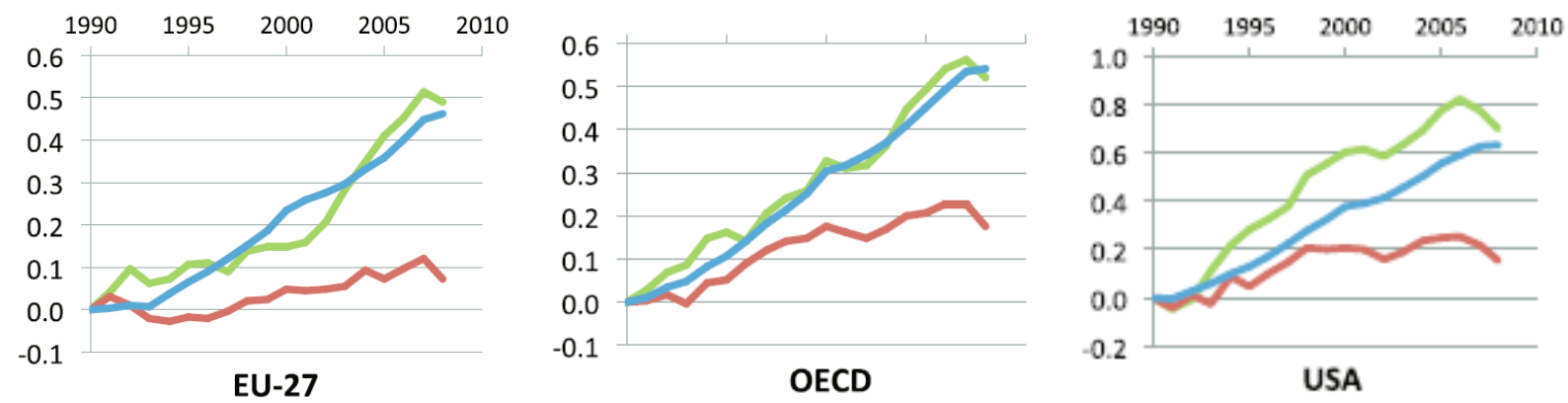

Figure 1. Material use trends for EU-27, OECD and USA, 1990-2008. Blue lines indicate GDP, red lines indicate DMC, and green lines indicate material footprint. Source: Wiedmann et al (2015).

According to Wiedmann et al (2015), the only significant cases of relative decoupling of GDP from material footprint have been China, India and South Africa. South Africa is the most notable of the three, with near-zero growth in material footprint since 1990, although no evidence of sustained absolute decoupling.

On a global scale, resource use has been rising on a steady trajectory. Krausmann et al (2009) show that global extraction and consumption of materials (including fossil fuels) increased 8 -fold during the period 1900 to 2005 , reaching 59 billion tons per year, growing at annual rates between 1 per cent and 4 per cent. Giljum et al. (2014) find that global consumption grew by 93.4 per cent between 1980 and 2009, at an average rate of 2.4 per cent per year, to reach a total of 67.6 billion tonnes. ${ }^{2}$ Materialflows.net (2015), which is run by the Vienna University of Economics and Business, offers data for the period 1980 to 2013 and shows that global material footprint grew 132 per cent, at an average rate of 2.5 per cent per year, to reach nearly 85 billion tons.

What is the relationship between global GDP and resource use? Krausmann et al (2009) show that during the $20^{\text {th }}$ century GDP grew at a faster rate ( 3 per cent per year) than resource use ( 2 per cent per year). This represents a relative decoupling or dematerialization of GDP growth, at a rate of about 1 per cent per year. But this changed in the $21^{\text {st }}$ century: the growth rate of global 
consumption increased between 2000 and 2005, averaging 3.7 per cent per year. As this matched the growth rate of GDP, no decoupling was achieved. Giljum et al (2014) also find that the growth rate of global consumption accelerated in the $21^{\text {st }}$ century, averaging 3.4 per cent per year between 2000 and 2009; once again, no decoupling was achieved. Wiedmann's global data shows a similar trend. Materialflows.net (2015) shows a period of modest growth of global material footprint from 1980 to 2002, at 1.78 per cent per year. As this was slower than the rate of GDP growth, some relative decoupling was achieved. However, the final decade from 2002 to 2013 shows an acceleration of global material use, at 3.85 per cent per year. ${ }^{3}$ Global material use rose more quickly than GDP during this decade. In other words, the material intensity of the world economy has been increasing in the $21^{\text {st }}$ century, not decreasing. The authors state: 'Currently, the world economy is therefore on a path of re-materialization and far away from any - even relative decoupling.'
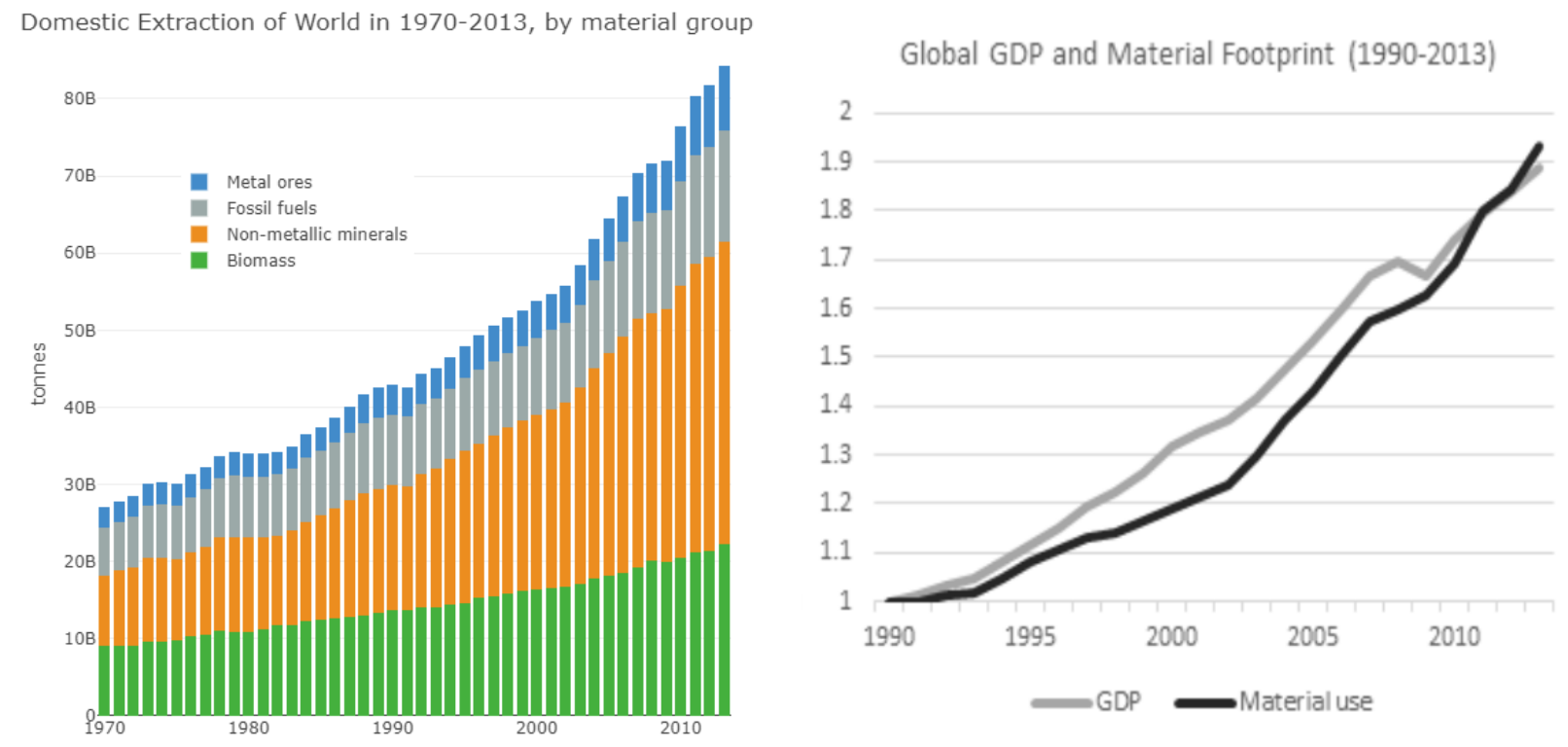

Figure 2. (a) Global material footprint, 1970-2013; (b) Change in global material footprint compared to change in global GDP (constant 2010 USD), 1990-2013. Source: Materialflows.net / World Bank

In sum: global historical trends show relative decoupling but no evidence of absolute decoupling, and $21^{\text {st }}$ century trends show not greater efficiency but rather worse efficiency, with recoupling occurring. Of course, future trajectories could potentially break with these trends if we change the composition and technology of the global economy (Grossman and Krueger 1995). What does the data about future prospects show?

One argument is that resource intensity will diminish as economies shift from manufacturing to services. Historical data do not support this theory, however. As a proportion of world GDP, services have grown from 63 per cent in 1997 to 69 per cent in 2015, according to World Bank data. Yet during this same period global material use has accelerated, outstripping global GDP growth. The same is true of high-income nations. Services represent 74 per cent of GDP in high-income nations (up from 69 per cent in 1997), but DMC has not diminished and material footprint is outpacing GDP growth. This may be because services turn require resourceintensive inputs (in other words, services embody significant amounts of materials), or because the 
income acquired from selling services is used to purchase resource-intensive consumer goods (Kallis 2017). Another possibility is that the resource intensity of primary and secondary sectors has increased to the point of outstripping any gains made by switching to services. Whatever the cause may be, there is no historical evidence that switching to services will, in and of itself, reduce the material throughput of the global economy.

Another argument is that technological innovation and government policy might drive decoupling in the future. This is the assumption advanced by the World Bank, OECD and UNEP green growth reports. To our knowledge, there are three major studies that examine this possibility on a global scale. We discuss their findings below.

Dittrich et al (2012) show that a 'business as usual' scenario will result in material use rising from 68 billion tons in 2008 to 180 billion tons in 2050. This scenario assumes that global South economies grow to the point where global average per capita consumption in 2030 will equal the OECD's per capita consumption in 2008. Dittrich et al conclude that this level of resource use is 'not an option for the future'. By contrast, their optimistic scenario assumes (a) medium population growth; (b) that all countries follow best practice in efficient resource use; and (c) that reduction of consumption of one material does not require higher consumption of another. Under this scenario, resource use reaches 93 billion tons by 2050. This represents relative decoupling, but no absolute reduction in material use.

In a second study, Schandl et al (2016) use a model based on 3 per cent average annual global GDP growth and explore three scenarios between 2010 and 2050. The reference scenario, with no significant change to environmental policies, shows that global resource use grows from 79.4 billion tonnes in 2010 to 183 billion tons in 2050 (similar to the Dittrich et al projection), with slight relative decoupling. The 'medium efficiency' scenario, with a carbon price of $\$ 25$ per ton of $\mathrm{CO} 2$ (rising by 4 per cent per year), shows that global resource use still grows steadily over the period, but at about half the rate of global GDP, reaching 130 billion tons by 2050 . The 'high efficiency' scenario, with a carbon price starting at $\$ 50$ (rising by 4 per cent per year to $\$ 236$ by 2050) plus a doubling in the material efficiency of the economy (from historical average improvements of 1.5 per cent per year up to 4.5 per cent per year), shows that global resource use still grows steadily, but at about one-fourth the rate of global GDP, reaching 95 billion tons in 2050 (again, similar to Dittrich et al).

It is important to note that the rate of material efficiency improvements that Schandl et al assume (viz., 4.5 per cent per year) has no empirical basis. They provide no evidence that such a rapid rate is possible to sustain. Yet even with this optimistic assumption, Schandl et al conclude: 'Our research shows that while some relative decoupling can be achieved in some scenarios, none would lead to an absolute reduction in... materials footprint.'

Finally, UNEP has developed a model that explores four different future scenarios, which they discuss in their 2017 report Assessing Global Resource Use (UNEP 2017c:42-45). Their reference scenario, extrapolating from existing trends, shows that global resource use rises steadily from 85 billion tons in 2015 to 186 billion tons by 2050 (similar to Dittrich et al and Schandle et $a l$ ). Their high efficiency scenario, by contrast, includes strong policy measures: (a) a global carbon price of $\$ 5$ per ton of CO2e in 2021, rising by 18.1 per cent per year to $\$ 573$ in 2050; (b) technological innovation that improves resource efficiency; (c) a resource extraction tax that increases the price of natural resources relative to other inputs; and (d) progressive changes to government regulations, planning and procurement policies (for full details of the model see UNEP $2017 \mathrm{~b}, 287 \mathrm{ff}$ ). The high efficiency scenario projects that global resource use rises to 132 billion 
tons in 2050. While some relative decoupling is achieved, there is no absolute reduction in resource use.

The UNEP projections are significantly worse than either Dittrich et al or Schandl et al predict. The model's authors, Ekins and Hughes, say this because they have incorporated the 'rebound effect' into their model (UNEP 2017c, $106 \mathrm{ff}$.). The rebound effect cancels out some gains in resource efficiency. This happens because such gains reduce the cost of a good or service, freeing up income and increasing effective demand (see Herring and Sorrell 2009 for a review of the literature). In light of these findings, UNEP acknowledges that improvements in resource efficiency will not be enough, in and of themselves, to achieve sustainability, or green growth. 'Resource efficiency alone is not enough. Productivity gains in today's linear production system are likely to lead to increased material demand through a combination of economic growth and rebound effects' (12). Instead, the report acknowledges that something else is needed. They suggest further investigation into the principles of a circular economy: 'a move from linear to circular material flows through a combination of extended product life cycles, intelligent product design and standardization, reuse, recycling and remanufacturing' (12). Improving circularity could reduce the ecological impact of material throughput, but only a small fraction of total throughput has circular potential. $44 \%$ is comprised of food and energy inputs, which are irreversibly degraded, and $27 \%$ is net addition to stocks of buildings and infrastructure (Haas et al 2015).

These models suggest that absolute decoupling is not feasible on a global scale in the context of continued economic growth. These are global studies, however. One might argue that when it comes to the question of whether green growth is possible, we need to look specifically at what rich nations might be able to achieve, given their higher capacity for technological development. Hatfield-Dodds et al (2016) have modelled a number of scenarios for Australia from 2015 to 2050, with results that have been widely cited in support of green growth theory. Their most optimistic scenario assumes high levels of policy-driven efficiency gains, with an overall 70 per cent drop in material intensity. They find that 'substantial economic and physical decoupling is possible,' with GDP increasing at an average rate of 2.41 per cent per year 'while associated environmental pressures ease (greenhouse gas emissions, water stress, native habitat loss)'. The model suggests that this can be accomplished without outsourcing environmental impact to other countries.

Hatfield-Dodds et al have come under criticism for this model, however. First, they provide no evidence for their assumption that a 70 per cent drop in material intensity is possible. Alexander et al (2018) have pointed out that this rate of efficiency improvement is baseless and unrealistic. Indeed, the Australian Bureau of Agricultural Economics (ABARE 2008) reports that efficiency is likely to improve by only 0.2 per cent to 0.5 per cent per year into the future - at most one-eighth of the rate that Hatfield-Dodds assume. Second, even if a 70 per cent drop in material intensity was possible, it appears that any resulting decrease in resource use may only be achieved over the short term. The optimistic scenario in the Hatfield-Dodds et al model shows that material use declines from 2015 to 2040, but begins to increase again thereafter.

Ward et al (2016) have tested the Hatfield-Dodds model over a longer period, to 2100. They assume a drop in material intensity by 2050 that is 50 per cent more than Hatfield-Dodds et al propose, for an even more optimistic scenario. They find that material extraction declines until 2050 (decoupling at an average rate of about 4 per cent per year) but then flattens off and rises steadily so that by 2100 material use is 20 per cent to 60 per cent higher than its initial value in 2015. While absolute decoupling from material extraction is achieved in the short term, in the longer term material extraction rises by 2.16 per cent per year, nearly matching the rate of GDP 
growth. Note that the indicator 'material extraction' is different from both DMC and material footprint, in that it does not include imports; the figures for DMC and material footprint for Australia would be significantly higher.

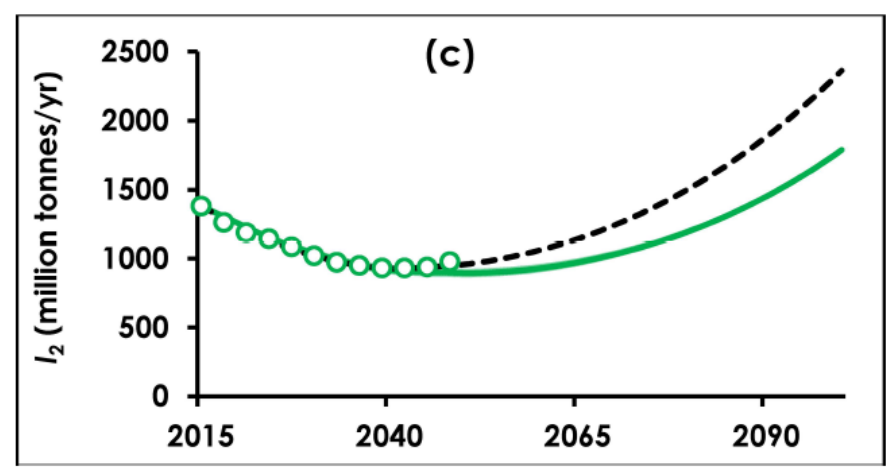

Figure 3. Projections for material extraction in Australia under highly optimistic conditions, 20152100. Green dots represent the Hatfield-Dodds projection to 2050. Source: Ward et al (2016)

Ward et al (2016) argue that this resurgence in material extraction happens because resource efficiency cannot improve forever, as eventually it approaches physical limits. They state: 'For nonsubstitutable resources such as land, water, raw materials and energy, we argue that whilst efficiency gains may be possible, there are minimum requirements for these resources that are ultimately governed by physical realities: for instance the photosynthetic limit to plant productivity and maximum trophic conversion efficiencies for animal production govern the minimum land required for agricultural output; physiological limits to crop water use efficiency govern minimum agricultural water use, and the upper limits to energy and material efficiencies govern minimum resource throughput required for economic production.'

As the physical limits of resource efficiency are reached, continued GDP growth drives resource use back up. Ward et al conclude that 'decoupling of GDP growth from resource use, whether relative or absolute, is at best only temporary. Permanent decoupling (absolute or relative) is impossible for essential, non-substitutable resources because the efficiency gains are ultimately governed by physical limits. Growth in GDP ultimately cannot plausibly be decoupled from growth in material and energy use, demonstrating categorically that GDP growth cannot be sustained indefinitely. It is therefore misleading to develop growth-oriented policy around the expectation that decoupling is possible.'

\section{Conclusions and discussion}

The empirical data suggest that absolute decoupling from resource use (a) may be possible in the short term in some rich nations with strong abatement policy, but only assuming theoretical efficiency gains that may be impossible to achieve in reality; (b) is not feasible on a global scale, even under best-case scenario policy conditions; and (c) is physically impossible to maintain in the longer term. In light of this data, we can conclude that green growth theory - in terms of resource use - lacks empirical support. We are not aware of any credible empirical models that contradict this conclusion. There are three counterpoints to consider, however:

First, this conclusion is sensitive to the baseline rate of GDP growth. The studies cited above project growth at 2-3 per cent per year. As the growth rate approaches zero, absolute decoupling becomes more feasible, and is likely to last longer. It is reasonable to expect that green 
growth could be accomplished at very low GDP growth rates, i.e., less than 1 per cent per year significantly lower than historical trends and projected pathways. ${ }^{4}$

Second, the studies cited above are based on the existing relationship between GDP and material throughput. They model the impact of known variables, such as efficiency improvements, technological innovation, taxes, shifts to services, etc. However, one might argue that it is theoretically possible to break the existing relationship between GDP and material throughput altogether. We reflect on this in the penultimate section of this paper.

Third, one might argue that the aggregate material footprint indicator obscures the possibility of shifting from high-impact resources to low-impact resources. It is true that different materials have different impacts, and that renewable and non-renewable materials have different kinds of sustainability thresholds, but the aggregate measure is nonetheless regarded as a useful proxy because all of the constituent material categories exhibit roughly the same trends as the total (i.e., they all increase with GDP growth). And because all materials have some impact, indefinite growth of any material category is not compatible with ecological principles.

It is important to point out that the standard for green growth we have used above is a conservative one, inasmuch as it regards any reduction of annual resource use, however small, as green. The academic literature on resource use is significantly more stringent than this. An emerging consensus holds that global material footprint needs to be reduced to 50 billion tons per year in order to be compatible with the planet's ecology (Dittrich et al. 2012, Hoekstra \& Wiedmann 2014, UNEP IRP 2014, Bringezu 2015). Bringezu (2015) goes further and suggests that this reduction needs to happen by 2050. Of course, there are reasons to be skeptical of global targets like this, as they combine renewable and non-renewable materials that should be treated separately, and because the impacts of material use are locally specific and thresholds should be tailored to local ecosystems (except in the case of fossil fuels and land-based biomass extraction, which affect greenhouse gas emissions). Still, the literature is clear that material footprint needs to be scaled down significantly from present levels. In other words, to be truly green, green growth requires not just any degree of absolute decoupling, but absolute decoupling that is rapid enough to meet ecological targets.

\section{Carbon emissions - is growth compatible with the Paris Agreement?}

Unlike with resource use, there is a steady long-term trend toward relative decoupling of GDP from carbon emissions, and we know that absolute reductions in carbon emissions are possible to achieve. When it comes to climate change, however, the objective is not simply to reduce emissions (a matter of flows), but to keep total emissions from exceeding specific carbon budgets (a matter of stocks). For green growth theory, then, the question is not only whether we can achieve absolute decoupling and reduce emissions, but whether we can reduce emissions fast enough to stay within the carbon budgets for $1.5 \mathrm{C}$ or $2 \mathrm{C}$, as per the Paris Agreement, while still continuing economic growth. 

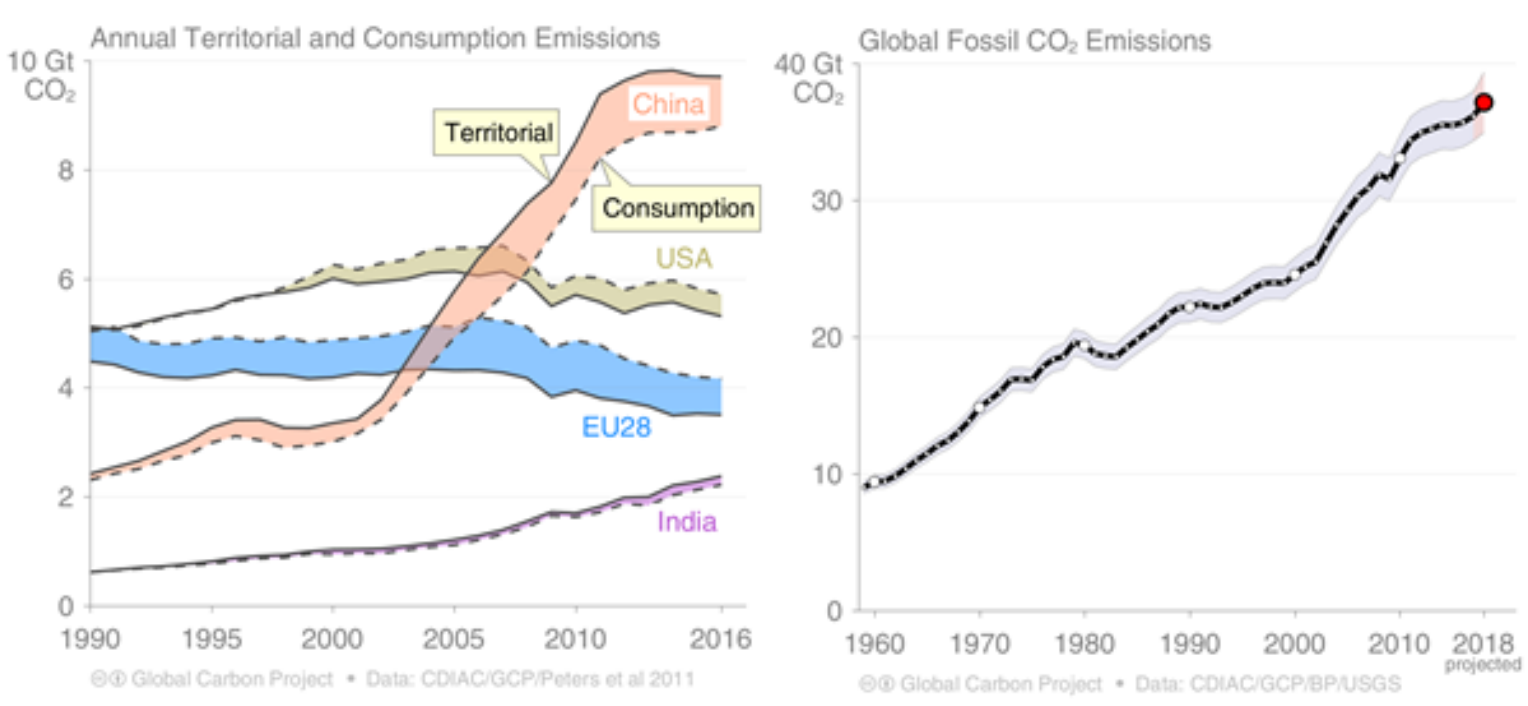

Figure 4: (a) Annual territorial and consumption CO2 emissions for select regions, 1990-2016; (b) Global CO2 emissions 1960-2018. Source: Global Carbon Budget 2018.

A number of high-income countries have seen declining emissions in the $21^{\text {st }}$ century, despite continued economic growth. Figure 4(a) above shows declining emissions in the US and EU28, in both territorial and consumption-based terms, from 2006 to 2016 (i.e., absolute decoupling). However, emissions from the global South have continued upward, albeit at a slower rate than GDP (i.e., relative decoupling). China's emissions declined slightly between 2014 and 2016 (a brief period of absolute decoupling), before growing again in 2017.

On a global level, $\mathrm{CO} 2$ emissions have increased steadily, falling only during periods of economic recession. Global emissions did level off in 2015 and 2016 while GDP continued to rise, prompting the International Energy Agency, a research arm of the OECD, to announce 'Decoupling of global emissions and economic growth confirmed' (IEA 2016), while media outlets celebrated 'peak emissions' (Meyer 2016). This news briefly came to constitute a key element of optimistic green growth narratives, until global emissions began to rise again in 2017 (1.6 per cent) and 2018 ( 2.7 per cent). Analysts attribute the temporary plateau to a shift in China away from coal and (mostly) toward oil and gas, and a shift in the US to natural gas. ${ }^{5}$ Once these shifts were complete, continued economic growth drove emissions up again.

Overall, global carbon productivity has been slowing. World Bank data shows that carbon productivity (CO2 per 2010 \$US GDP) improved steadily from 1960 to 2000, with decarbonization at an average rate of 1.28 per cent per year (relative decoupling). However, from 2000 to 2014 there was no improvement in carbon productivity - in other words, not even relative decoupling has been achieved in the $21^{\text {st }}$ century. ${ }^{6}$ High-income nations have done better, at least in terms of territorial emissions (the World Bank does not track consumption-based emissions), but even so progress has slowed, from an average rate of 1.91 per cent per year from 1970 to 2000, down to 1.61 per cent per year from 2000 to 2014.

Existing trends are incompatible with the Paris Agreement targets. Business-as-usual is set to lead to 4.2 degrees of warming (2.5 degrees to 5.5 degrees) by 2100 . Even with the Nationally Determined Contributions and Intended Nationally Determined Contributions under the Paris Agreement, global warming is still projected to reach 3.3 degrees (1.9 degrees to 4.4 degrees) - an 
improvement over the BAU scenario but still far exceeding the $1.5 \mathrm{C}$ and $2 \mathrm{C}$ thresholds. ${ }^{7}$ In order to keep warming below these thresholds, the world will have to make much more aggressive emissions reductions.

The IPCC's Fifth Assessment Report (AR5) includes 116 mitigation scenarios that are consistent with Representative Concentration Pathway 2.6 (RCP2.6), which offers the best chances of staying below 2C. All of these scenarios are green growth scenarios in that they stabilise global temperatures while global GDP continues to rise. Rising GDP is a built-in feature of the Shared Socio-Economic Pathways (SSPs), which form the basis for the IPCC mitigation scenarios (Kuhnhenn 2018). AR5 warns, however, that these scenarios 'typically involve temporary overshoot of atmospheric concentrations' and 'typically rely on the availability and widespread deployment of bioenergy with carbon capture and storage (BECCS)' (2014:23). Indeed, the vast majority scenarios for 2C (101 of the 116) rely on BECCS to the point of achieving negative emissions. ${ }^{8}$ BECCS entails growing large tree plantations to sequester $\mathrm{CO} 2$ from the atmosphere, harvesting biomass, burning it for energy, capturing the $\mathrm{CO} 2$ emissions at source and storing it underground. Relying on these 'negative emissions technologies' allows for a much larger carbon budget (about double the actual size) by assuming that we can successfully reduce global atmospheric carbon in the second half of the century.

BECCS is highly controversial among climate scientists. It was first proposed by Obersteiner et al (2001) and Keith (2001) at the turn of the century. IPCC modeling teams began including it in their scenarios from 2005, despite having no firm evidence of its feasibility. With the publication of AR5, BECCS was enshrined as a dominant assumption. Obersteiner has expressed alarm at the rapid uptake of his idea; he considers BECCS to be what he calls a 'riskmanagement strategy', or a 'backstop technology' in case climate feedback loops turn out to be worse than expected, and says the IPCC has 'misused' it by including it in regular scenarios to take pressure off of conventional mitigation pathways (i.e., emissions reductions) (Hickman 2016). In Keith's (2001) initial formulation of the idea, he noted that while 'measured use' of biomass could help mitigate environmental problems, 'large scale use of cropped biomass will not.'

Anderson and Peters (2016) point out that the 'allure' of BECCS is due to the fact that it allows politicians to postpone the need for rapid emissions reductions: 'BECCS licenses the ongoing combustion of fossil fuels while ostensibly fulfilling the Paris Commitments.' There are a number of concerns. First, the viability of power generation with CCS has never been proven to be economically viable or scalable; it would require the construction of 15,000 facilities (Peters 2017). Second, the scale of biomass assumed in the AR5 scenarios would require plantations covering land two to three times the size of India, which raises questions about land availability, competition with food production, carbon neutrality, and biodiversity loss (Smith et al 2015; Heck et al 2018).

Third, the necessary storage capacity may not exist (De Coninck and Benson 2014; Global CCS Institute 2015). Anderson and Peters conclude that 'BECCS thus remains a highly speculative technology' and that relying on it is therefore 'an unjust and high stakes gamble': if it is unsuccessful, 'society will be locked into a high-temperature pathway.' This conclusion is shared by a growing number of scientists (e.g., Fuss et al. 2014, Vaughan and Gough 2016. Larkin et al. 2017, van Vuuren et al. 2017), and by the European Academies' Science Advisory Council (2018).

It is not clear that we can justifiably rely on BECCS, an unproven technology, to underwrite green growth theory. If we accept this point, then we must return to asking whether it is possible to maintain growth without relying on BECCS to stay within the carbon budgets consistent with the Paris Agreement. Without BECCS, global emissions need to fall to net zero by 2050 for $1.5 \mathrm{C}$, or by 2075 for $2 \mathrm{C}^{9}{ }^{9}$ This entails reductions of 6.8 per cent per year and 4 per cent per year, 
respectively. Theoretically, this can be accomplished with (a) a rapid shift to 100 per cent renewable energy to eliminate emissions from fossil fuel combustion (Jacobson and Delucchi 2011); plus (b) afforestation and soil regeneration to eliminate emissions from land use change; plus (c) a shift to alternative industrial processes to eliminate emissions from the production of cement, steel, and plastic. The question is, can all of this be accomplished quickly enough?
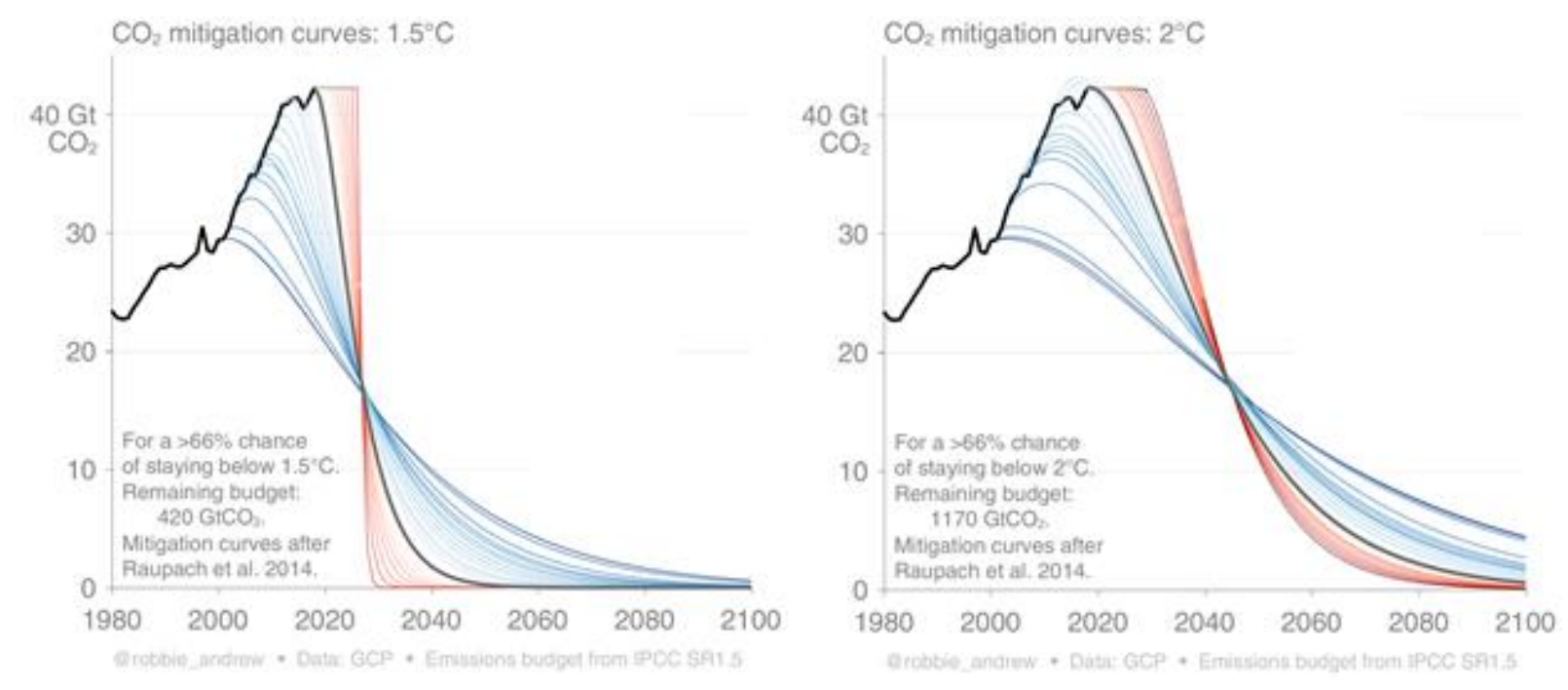

Figure 5. CO2 mitigations curves for 1.5C and 2C. Source: IPCC (2018)

Only 6 of the 116 scenarios for 2C in AR5 exclude BECCS. These work by assuming 'optimal full technology' in all other areas, plus mass afforestation, and with high mitigation costs. These represent theoretically possible pathways, but without any empirical evidence as to their feasibility.

Results of empirical studies are not promising. Schandl et al (2016) model what might be achieved with aggressive mitigation policies, without relying on BECCS. Their high-efficiency scenario has a carbon price starting at $\$ 50$ per ton (rising by 4 per cent per year to $\$ 236$ by 2050) plus a doubling in the material efficiency of the economy due to technological innovations (improving from a historical average rate of 1.5 per cent per year up to 4.5 per cent). Schandl et al provide no evidence for the feasibility of the efficiency improvements that they assume. Even so, the result shows that with global growth of 3 per cent per year, annual emissions plateau to 2050 but do not decline. In this scenario, growth in energy demand outstrips the rate of decarbonization, violating the carbon budgets for $1.5 \mathrm{C}$ and $2 \mathrm{C}$.

The International Renewable Energy Association (IRENA 2018) have modelled a scenario for continued GDP growth compatible with $2 \mathrm{C}$ by relying on a rapid shift to renewable energy (consistent with Jacobson and Delucchi 2011). The scenario requires adding 12,200 GW of solar and wind capacity by 2050, with a dramatic increase in installation rates (2.3 to 4.6 times faster than the present). ${ }^{10}$ The scenario also requires that the energy intensity of the global economy falls by two-thirds (by 2.8 per cent per year, double the historical rate), lowering energy demand in 2050 to slightly less than 2015 levels. ${ }^{11}$ This is feasible inasmuch as the transition to wind and solar itself improves energy efficiency (Jacobson and Delucchi 2011). ${ }^{12}$ Still, even this optimistic scenario accomplishes only 90 per cent of the necessary emissions reductions for $2 \mathrm{C}$ (likely because it pays 
no attention to emissions from land use change and cement production). The model relies on negative emissions technology to cover most of the remainder.

Van Vuuren et al (2018) consider 'alternative pathways' for meeting the Paris Agreement targets without relying on widespread use of negative emissions technologies. They model rising GDP in accordance with SSP2. In addition to a carbon tax and other aggressive mitigation strategies, their optimistic scenario includes the following settings: global population peaks at 8.4 billion in 2050 and declines to 6.9 billion by 2100 , meat consumption declines by 80 per cent by 2050, all new cars and airplanes are efficient from 2025, the world shifts to the most efficient technologies for steel and cement production, etc. Even with these highly optimistic assumptions in place, they find that the pressures of continued growth drive emissions to exceed the carbon budgets for $1.5 \mathrm{C}$ and $2 \mathrm{C}$, without negative emissions technologies.

Another way to approach this question is by looking at projected rates of decoupling. If we assume global GDP continues to grow at 3 per cent per year (the average from 2010-2014), then decoupling must occur at a rate of 10.5 per cent per year for $1.5 \mathrm{C}$, or 7.3 per cent per year for $2 \mathrm{C}$. If global GDP grows at 2.1 per cent per year (as PWC predicts), then decoupling must occur at 9.6 per cent per year for $1.5 \mathrm{C}$, or 6.4 per cent per year for $2 \mathrm{C}$. All of these targets are beyond what existing empirical models indicate is feasible. The Schandl et al model indicates that decoupling can happen by at most 3 per cent per year under optimistic conditions. Other models arrive at similar conclusions. The IPCC's (2000) global best-case-scenario projects decoupling of 3.3 per cent per year without BECCS. The C-ROADS tool (developed by Climate Interactive and MIT Sloan) projects decoupling of at most 4 per cent per year under the most aggressive possible abatement policies: high subsidies for renewables and nuclear power, plus high taxes on oil, gas and coal. All of these results fall short of the decoupling rate that must be achieved if the global economy continues to grow at expected rates. Holz et al (2018) find that if we rule out widespread use of negative emissions technologies, the required rate of decarbonization for meeting the Paris Agreement is 'well outside what is currently deemed achievable, based on historical evidence and standard modelling.'

The challenge is even more difficult for rich nations. Anderson and Bows (2011) have modeled the emissions reductions necessary for achieving a 50 per cent chance of staying under $2 \mathrm{C}$ (more relaxed than the two-thirds chance that the UNFCC calls for), without BECCS. They proceed from the principle of 'common but differentiated responsibility', whereby rich nations (Annex-1 nations) make more aggressive emissions reductions than poor nations, owing to their greater historical responsibility for emissions and their greater capacity for managing the costs of transition. They assume that Non-Annex 1 nations defer peak emissions until 2025, and thereafter reduce emissions by 7 per cent per year. They acknowledge that these are extremely ambitious assumptions but consider them to be the most feasible compromise between practicality and equity. To stay within the remaining carbon budget, Annex 1 nations need to reduce emissions by 8-10 per cent per year, beginning in 2015. This model was developed with data up to 2010; as the remaining carbon budget is now smaller, Anderson (2018) estimates that Annex 1 nations need to reduce emissions by 12 per cent per year.

If we accept that Annex 1 nations need to achieve emissions reductions of 12 per cent per year, and if we assume that GDP growth in Annex 1 nations continues at 1.86 per cent per year (the average from 2010-2014), then decoupling must occur at a rate of 15.8 per cent per year. ${ }^{13}$ For perspective, this is eight times faster than the historic rate of decoupling in Annex 1 nations (viz., 1.9 per cent per year from 1970 to 2013), and it is important to bear in mind that the rate of decoupling has generally slowed over this period. ${ }^{14}$ It also exceeds the decoupling rate implied by 
the average G20 Nationally Determined Contributions under the Paris Agreement (viz., 3 per cent per year) by a factor of five.

There is one empirical model that feasibly accomplishes emissions reductions consistent with the Paris Agreement, without relying on negative emissions technologies. Published by Grubler et al (2018), it was included in the IPCC Special Report on 1.5C (2018) in response to growing critiques of the IPCC's reliance on BECCS. The scenario, known as 'Low Energy Demand' (LED), accomplishes emissions reductions compatible with $1.5 \mathrm{C}$ by reducing global energy demand by 40 per cent by 2050 . In addition to decarbonization and afforestation, the key feature of this scenario is that global material production and consumption declines significantly: 'The aggregate total material output decreases by close to 20 per cent from today, one-third due to dematerialization, and two-thirds due to improvements in material efficiency.' Dematerialization is accomplished by shifting away from private ownership of key commodities (like cars) towards sharing-based models. LED differentiates between the global North and South. Industrial activity declines by 42 per cent in the North and 12 per cent in the South. With efficiency improvements, this translates into industrial energy demand declining by 57 per cent in the North and 23 per cent in the South.

The LED scenario projects continued GDP growth at just over 2 per cent per year, which would make it consistent with green growth theory. However, the empirical basis for this GDP trend is not robust. It is derived from the MESSAGE-Globium model, which calculates GDP from only two inputs: labour supply (population size and productivity) and energy. The low energy demand in the LED scenario does not affect growth because it is offset by efficiency improvements. As the model is insensitive to changes in material throughput, reductions in production and consumption do not affect output. The paper offers no evidence that GDP will continue to grow despite such reductions. Charlie Wilson, one of the paper's authors, acknowledged that 'we did not consider broader questions of GDP growth or degrowth, and we did not explicitly report relationships between our scenario and GDP outcomes for this reason., ${ }^{15}$

\section{Conclusions and discussion}

The empirical data demonstrate that while absolute decoupling of GDP from emissions is possible and is already happening in some regions, it is unlikely to happen fast enough to respect the carbon budgets for $1.5 \mathrm{C}$ and $2 \mathrm{C}$ against a background of continued economic growth. Growth increases energy demand, making the transition to renewable energy more difficult, and increases emissions from land use change and industrial processes. Models that do project green growth within the constraints of the Paris Agreement rely heavily on negative emissions technologies that are either unproven or dangerous at scale. Without these technologies, the rates of decarbonization required for $1.5 \mathrm{C}$ or $2 \mathrm{C}$ are significantly steeper than extant models suggest is feasible even with aggressive mitigation policies.

This conclusion changes somewhat if we adjust the baseline growth rate. All of the studies cited above project global GDP growth at 2-3 per cent per year. A lower rate of growth requires a lower rate of decarbonization. A growth rate of 0 per cent requires decarbonization of 6.8 per cent per year (for 1.5C) and 4 per cent per year (for 2C). There is no empirical evidence that 6.8 per cent can be achieved on a global scale, but 4 per cent is nearly within reach. In other words, it is empirically feasible to achieve green growth within a carbon budget for $2 \mathrm{C}$ with the most aggressive possible mitigation policies if the growth rate is very close to zero and if mitigation starts immediately. This conclusion is in line with research by Schroder and Storm (2018), which finds 
that reducing emissions in line with the $2 \mathrm{C}$ target is feasible (under optimistic assumptions) only if global economic growth is less than 0.45 per cent per year. This conclusion does not hold for $1.5 \mathrm{C}$, however; emissions reductions in line with $1.5 \mathrm{C}$ are not empirically feasible except in a de-growth scenario.

\section{Theoretical possibilities}

As John O’Neill (2017) writes, whereas 'it is logically possible to have increasing GDP and a decreasing physical and energy throughput in an economy ... it is a fallacy to move from claims about what is logically possible to claims about what is physically possible and another from what is physically possible to what is empirically actual'. Green growth, we have shown, is not empirically actual - but is it possible in theory?

This question is often approached in terms of the IPAT equation (Environmental Impact $=$ Population * Affluence * Technology), which says that the impact of an economy (e.g., tons of C per capita) is equal to the scale of the economy (GDP per capita) times its efficiency (e.g., GDP per tons of carbon). Efficiency is in principle determined by technology and policy and there is no $a$ priori reason why it cannot increase faster than scale, or even as fast as necessary to reduce impact to a sustainable level. Furthermore, insofar as GDP measures what people are willing to pay for things, as opposed to the amount of energy and resources people consume, there is no reason why the economy cannot in theory grow using progressively less energy and resources: peoples' preferences may shift to goods and services with ever-lower energy and material requirements. One may conclude then that absolute decoupling should theoretically be possible - and in fact this is precisely the reason that advocates of green growth are not deterred by claims that it has not happened yet and does not seem likely to happen in the future. They attribute this to lack of effort.

Ward et al's (2016) study provides perhaps the most compelling counter-argument to this claim. As there is a thermodynamically defined maximum of efficiency, indefinite growth will sooner or later lead to increase in resource and energy use. Any absolute reductions due to substitution or efficiency will at best be temporary. Imagine a hypothetical economy powered by the sun, with a steady supply of food and necessities from renewable sources where goods are reused and materials recycled. In the transition to such an economy, resource use will decline. But even such an economy will still have some minimal requirement for material inputs, land, etc - so after the transition takes place then any further growth in this economy will lead to a growth in resource use. Given that compound growth quickly turns to infinity, so too will resource use and impact.

One may respond by arguing that we are still far from reaching limits in efficiency and substitution. We cannot rule out substitutions or technological breakthroughs that will push such limits so far into the future as to render them irrelevant (e.g. nuclear fusion, 100 per cent recycling of materials fueled by fusion or solar power, etc). Plus, the economy still has significant room for structural change towards less resource intensive services. In other words - the argument might go - maybe green growth is not sustainable indefinitely, but it can nonetheless happen now and can be sustained for a time horizon relevant for our civilization (although note that Ward et al indicate that the limits of resource efficiency may be reached by 2050).

So let us assume that green growth is theoretically possible in the short to medium term. Still, we must ask if there is a fundamental, as opposed to historically contingent reason why it has 
not happened yet. Is there some underlying reason why throughput and output are so tightly coupled in the empirical record ? $^{16}$

It is worth noting that the IPAT model gives the impression that $\mathrm{A}$ and $\mathrm{T}$, or scale and efficiency, are independent factors, when in fact they affect one another (Ekins 2012). But note that IPAT is a tautology, true by definition of the quantities involved, and should not be confused with a causal model. Furthermore, P, A and T are not independent from one another. We know for example from basic growth economics that technological development $(\mathrm{T})$ causes economic growth and growth in consumption (A). Ecological economists have also shown that the more efficiently an economy uses resources, the more it grows, and the more resources it ends up consuming - the so-called Jevons' paradox (Polimeni et al. 2008). This is not just a matter of rebounds eating efficiency gains at the micro-level - it refers to a more fundamental macro-mechanism through which industrial economies grow by using resources more productively. For example, when technology improves labour productivity, we expect that this will lead to more growth and more jobs as the relative cost of labour declines - why some expect this to work differently in relation to resources is not clear (Kallis 2018).

Another fundamental reason why efficiency might be coupled with scale is that as we know from biology and ecology, the metabolism of a larger organism, say an elephant, is more efficient than that of a smaller one, say a mouse, but this is because the elephant is bigger (Polimeni et al 2008). It is true that relative resource or energy decoupling often accompanies the growth of an economy - but this might simply be an artifact of scale. And it does not follow that more and more relative decoupling will amount to absolute decoupling. The U.S. economy, like an elephant, could not be so much bigger than others were it not also more efficient, and it is big because it is efficient - but this doesn't mean that by getting bigger and bigger it will burn less energy, just as an elephant does not burn fewer calories than amouse. All this does not amount to a theoretical refutation of absolute decoupling, but it shows that there might exist a more fundamental mechanism that links the scale of an economy to its throughput that is worth exploring.

That said, one might argue that unlike the scale of an animal, the scale of the economy (i.e., GDP) is a measure of value, not of physical size, and it can therefore grow without limit even while resource and energy throughput diminishes. GDP, one might argue, merely measures what people are willing to pay for, which is not necessarily connected to the use of resources and energy.

Can value grow independently of throughput? This begs for a clear definition of value, or a theory of value. Unfortunately, the green growth literature provides no such theory. There are two general possibilities that we might consider. (1) The neoclassical theory of value, whereby value represents utility (how useful we find goods), which is revealed in prices (how much we are willing to pay for them). In this schema, GDP is the amount of valuable goods and services bought and sold, multiplied by their value. To the extent that the green growth literature considers GDP to be a proxy for total value, we can assume that it accepts this neoclassical theory of value. (2) The labour or energy theories of value. These claim that value is ultimately determined by the work or energy that goes into production, hinting at a more fundamental coupling between value and throughput (Kallis 2018). From this perspective, value cannot grow without more human labour or energy put into production.

Neither the neo-classical nor the labour or energy theories of value have been empirically proven; in other words, they cannot accurately predict the price at which goods trade. It is impossible to calculate the total labour or energy that has gone into the production of a good, or the utility it provides. Indeed, no one has ever independently measured utility to test whether it correlates with prices or willingness to pay (Sagoff 2008). We therefore do not have a theory of 
value that allows us to determine whether value can be absolutely decoupled from throughput. Of course, one might say there is a third way: we can think of value as the sum of all the 'values' people hold. There is of course no reason why the things a society values cannot increase while throughput decreases. There are two problems with this approach, however. First, if values are incommensurable, it is impossible to aggregate them and determine whether total value is growing or not. Second, one can imagine a society that values above all the quality of the natural environment; such a value could of course grow while throughput decreases, but to call such a scenario 'green growth' is to stretch the meaning of the term beyond relevance.

In sum, it cannot be proven that green growth of value is theoretically possible, unless we accept a framework that makes it by definition possible - a framework that assumes that value and output are determined by some undefined, limitless quality called utility that is uncoupled from the physical world. Conversely, though, and by the same token, it cannot be proven either that green growth is theoretically impossible, at least not as long as ultimate limits in efficiency and substitution have not been reached. As a result, our only reliable guide to the green growth/decoupling question must be empirical. And, as we have demonstrated, existing empirical studies demonstrate that green growth is at best highly unlikely. One may insist that green growth hasn't occurred because it has not been tried, the fact that it hasn't been empirically observed till now then becoming irrelevant. We follow instead a more precautionary approach and argue that policy should be made on the basis of robust empirical evidence, rather than on the basis of speculative theoretical possibilities, particularly given the severity of the crisis that is at stake.

\section{Conclusion}

This review finds that extant empirical evidence does not support the theory of green growth. This is clear in two key registers. (1) Green growth requires that we achieve permanent absolute decoupling of resource use from GDP. Empirical projections show no absolute decoupling at a global scale, even under highly optimistic conditions. While some models show that absolute decoupling may be achieved in high-income nations under highly optimistic conditions, they indicate that it is not possible to sustain this trajectory in the long term. (2) Green growth also requires that we achieve permanent absolute decoupling of carbon emissions from GDP, and at a rate rapid enough to prevent us from exceeding the carbon budget for $1.5 \mathrm{C}$ or $2 \mathrm{C}$. While absolute decoupling is possible at both national and global scales (and indeed has already been achieved in some regions), and while it is technically possible to decouple in line with the carbon budget for $1.5 \mathrm{C}$ or $2 \mathrm{C}$, empirical projections show that this is unlikely to be achieved, even under highly optimistic conditions.

The empirical evidence opens up questions about the legitimacy of World Bank and OECD efforts to promote green growth as a route out of ecological emergency, and suggests that any policy programs that rely on green growth assumptions - such as the Sustainable Development Goals - need urgently to be revisited. That green growth remains a theoretical possibility is no reason to design policy around it when the facts are pointing in the opposite direction.

Of course, we need all of the technological innovations we can get, and we need to gear government policy toward driving these innovations, but this will not be enough in and of itself. The evidence presented above indicates that in order for efficiency gains to be effective, we will need to scale down aggregate economic activity too. It is more plausible that we will be able to achieve the necessary reductions in resource use and emissions without growth than with growth. Indeed, there are no scientific grounds upon which we should not question growth, if our goal is to 
avoid dangerous climate change and ecological breakdown. Staying within planetary boundaries may require a de-growth of production and consumption in high-consuming nations (Victor 2008, Jackson 2009, Alier 2009, Kallis 2011, Kallis et al. 2012), and a shift away from the narrow growth-focused development agenda in the global South. As Gough (2017) notes, combatting climate change might require not only new clean and efficient energy technologies, but also a reduction and re-composition of consumption, with a shift from carbon-intensive to low or zero carbon sectors. Legislative limits, green taxes, shifts in public investment and working hourreductions or new social security institutions such as a basic income all have a role to play in such a transition (Gough 2017, Kallis 2018). The objective could be to find ways to decouple prosperity and development from growth (e.g. Jackson 2009, O'Neill et al. 2018) rather than to continue to chase the phantom of green growth.

It seems likely that the insistence on green growth is politically motivated. The assumption is that it is not politically acceptable to question economic growth and that no nation would voluntary limit growth in the name of the climate or environment; therefore green growth must be true, since the alternative is disaster. But it might well be the case that, as Wackernagel and Rees (1998) put it, 'the politically acceptable is ecologically disastrous while the ecologically necessary is politically impossible'. As scientists we should not let political expediency shape our view of facts. We should assess the facts and then draw conclusions, rather than start with palatable conclusions and then foreclose inconvenient facts.

\section{Acknowledgement}

Kallis's research benefited from support from the Spanish Ministry of Economy and Competitiveness (MINECO) under the "María de Maeztu" Unit of Excellence (MDM-2015-0552) and the COSMOS (CSO2017-88212-R) grant.

\section{References}

1. Alexander, S., Rutherford, J., and Floyd, J. 2018. A Critique of the Australian National Outlook Decoupling Strategy: A 'Limits to Growth' Perspective. Ecological Economics, $145,10-17$.

2. Alier, J. M. 2009. Socially Sustainable Economic De-growth. Development and change, 40(6), 1099-1119.

3. Anderson, K., and Bows, A. 2011. Beyond 'dangerous' climate change: emission scenarios for a new world. Philosophical Transactions of the Royal Society of London A: Mathematical, Physical and Engineering Sciences 369, no. 1934: 20-44.

4. Anderson, K., and Peters, G. 2016. The trouble with negative emissions. Science, 354 (6309), pp.182-183.

5. Australian Bureau of Agricultural and Resource Economics (ABARE). (2008). Energy in Australia, Canberra.

6. Ayres, R.U., and Simonis, U.E. 1993. Industrial Metabolism: Restructuring for Sustainable Development. Tokyo, New York: UN University Press. 
7. Ayres, R.U., Ayres, L.W., and Frankl, P. 1996. Industrial Ecology: Towards Closing the Materials Cycle. Edward Elgar, Cheltenham.

8. Bringezu et al. 2015. Possible target corridor for sustainable use of global material resources. Resources 4: 25-54.

9. Ceballos, G., Ehrlich, P. R., Barnosky, A. D., García, A., Pringle, R. M., and Palmer, T. M. 2015. Accelerated modern human-induced species losses: Entering the sixth mass extinction. Science Advances, 1(5).

10. Ceballos, G., Ehrlich, P. R., and Dirzo, R. 2017. Biological annihilation via the ongoing sixth mass extinction signaled by vertebrate population losses and declines. Proceedings of the National Academy of Sciences, 114(30), E6089-E6096.

11. CCC. 2008. Building a low-carbon economy-the UK's contribution to tackling climate change. Norwich, UK: The Stationery Office.

12. Daly, H. 2013. Sustainable Development: Definitions, Principles, Policies. Mechanism of Economic Regulation 3.

13. Dasgupta, S., Laplante, B., Wang, H. and Wheeler, D. 2002. Confronting the environmental Kuznets curve. Journal of economic perspectives, 16(1), pp.147-168.

14. De Coninck, H., and Benson, S. M. 2014. Carbon dioxide capture and storage: issues and prospects. Annual Review of Environment Resources 39:243-270.

15. Dittrich, M., Giljum, S., Lutter, S., and Polzin, C. 2012. Green economies around the world. Implications of resource use for development and the environment. Vienna: SERI.

16. Ekins, P. 2012. Sustainable growth revisited: technology, economics and policy. Mineral Economics, 24(2-3), pp.59-77.

17. Erkman, S. 1997. Industrial ecology: an historical view. Journal of Cleaner Production 5 (1e2), $1 \mathrm{e} 10$.

18. European Academies Science Advisory Council. 2018. Negative Emission Technologies: What role in meeting Paris Agreement targets? EASAC Policy Report 35.

19. Fuss, S., Canadell, J.G., Peters, G., Tavoni, M., Andrew, R., Ciais, P., Jackson, R. et al. 2014. Betting on negative emissions. Nature Climate Change 4, no. 10:850-853.

20. Gough, I. 2017. Heat, greed and human need: Climate change, capitalism and sustainable wellbeing. Edward Elgar Publishing. 
21. Giljum, S., Dittrich, M., Lieber, M., and Lutter, S. 2014 Global patterns of material flows and their socio-economic and environmental implications: a MFA study on all countries world-wide from 1980 to 2009. Resources 3, no. 1: 319-339.

22. Global Carbon Budget 2018. 2018. Global Carbon Project. Accessed December 15, 2018. http://www.globalcarbonproject.org/carbonbudget/

23. Global CCS Institute. 2015. Global Status of CCS 2015: Summary Report

24. Goodall, C. 2011. 'Peak Stuff': Did the UK reach a maximum use of material resources in the early part of the last decade. A research paper for Carbon Commentary, 13.

25. Grubler, Arnulf et al. 2018. A low energy demand scenario for meeting the 1.5C target and sustainable development goals without negative emissions technologies. Nature Energy 3:515-527.

26. Gutowski T., Cooper, D., and Sahni, S. 2017. Why we use more materials. Philosophical Transactions of the Royal Society A 375.

27. Haas, W., Krausmann, F., Wiedenhofer, D. and Heinz, M., 2015. How circular is the global economy?: An assessment of material flows, waste production, and recycling in the European Union and the world in 2005. Journal of Industrial Ecology, 19(5), pp.765-777.

28. Hatfield-Dodds S., Schandl, H., Adams, PD., Baynes, TM., Brinsmead, TS., Bryan, BA., et al. 2015. Australia is 'free to choose' economic growth and falling environmental pressures. Nature 527(7576): 49-53.

29. Heck, V. et al. 2018. 'Biomass-based negative emissions difficult to reconcile with planetary boundaries,' Nature Climate Change 8.

30. Hoekstra, A. Y., and Wiedmann, T. O. 2014. Humanity's unsustainable environmental footprint. Science 344, 1114-1117.

31. Hof, A., den Elzen, M. G. J., and van Vuuren, D. 2009. The use of economic analysis in climate change appraisal of post-2012 climate policy. Bilthoven, The Netherlands: Netherlands Environmental Assessment Agency.

32. Hickman, L. 2016. The History of BECCS, Carbon Brief. https://www.carbonbrief.org/beccs-the-story-of-climate-changes-saviour-technology

33. Holz, C., Siegel, L. S., Johnston, E., Jones, A. P., \& Sterman, J. (2018). Ratcheting ambition to limit warming to $1.5 \mathrm{C}$-trade-offs between emission reductions and carbon dioxide removal. Environmental Research Letters, 13(6), 064028. 
34. International Energy Agency. 2016. Decoupling of global emissions and economic growth confirmed. October. https://www.iea.org/newsroom/news/2016/march/decoupling-ofglobal-emissions-and-economic-growth-confirmed.html

35. IPCC. 2000. Special Report on Emissions Scenarios.

36. IPCC. 2014. Climate change 2014 Synthesis Report - Summary for Policymakers.

37. IPCC. 2018. Global Warming of 1.5C - Summary for Policymakers. Switzerland: IPCC.

38. IRENA 2018. Global energy transformation: A roadmap to 2050. International Renewable Energy Agency, Abu Dhabi.

39. Jackson, T. 2009. Prosperity without growth: The transition to a sustainable economy.

40. Jacobs, M. 2013. Green growth. In: Falkner, Robert, (ed.) The Handbook of Global Climate and Environment Policy. Wiley-Blackwell, Chichester, UK, pp. 197-214

41. Jacobson, M. Z., and Delucchi, M. 2011. Providing all global energy with wind, water, and solar power, Part I: Technologies, energy resources, quantities and areas of infrastructure, and materials.' Energy policy 39, no. 3: 1154-1169.

42. Larkin, A. et al. 2017. What if negative emissions technologies fail at scale? Climate Policy.

43. Kallis, G. 2011. In defence of degrowth. Ecological Economics, 70(5), 873-880.

44. Kallis, G., Kerschner, C., and Martinez-Alier, J. 2012. The economics of degrowth. Ecological Economics 84.

45. Kallis, G. 2017. Radical dematerialization and degrowth. Philosophical Transactions of the Royal Society A 375, no. 2095.

46. Kallis, G. 2018. Degrowth. Newcastle-upon-Tyne: Agenda Publishing.

47. Keith, D. W. 2001 Sinks, energy crops and land use: coherent climate policy demands an integrated analysis of biomass. Climatic change 49, no. 1: 1-10.

48. Krausmann, F., Gingrich, S., Eisenmenger, N., Erb, K., Haberl, H., and Fischer-Kowalski, M. 2009. Growth in global materials use, GDP and population during the 20th century. Ecological Economics 68, no. 10: 2696-2705.

49. Kuhnhenn, K. 2018. Economic Growth in mitigation scenarios: A blind spot in climate science. Heinrich Boll Foundation. 
50. Meyer R. 2016. Not Doomed Yet: The Biggest Political-Economy News This Millennium. The Atlantic. April. Available: http://www.theatlantic.com/science/archive/2016/04/flatemissions-economy-growth/

51. Obersteiner, M., Azar, C., Kossmeier, S., Mechler, R., Moellersten, K., Nilsson, S., Read, P., Yamagata, Y., and Yan, J. 2001. Managing climate risk. International Institute for Applied Systems Analysis.

52. O’Neill, D.W., Fanning, A.L., Lamb, W.F. and Steinberger, J.K. 2018. A good life for all within planetary boundaries. Nature Sustainability, 1(2), p.88.

53. O’Neill, J. 2017. Happiness, Austerity and Inequality. In Good Life Beyond Growth: Critical Perspectives, H. Rosa (ed.), 141-152. Abingdon: Routledge.

54. Organisation for Economic Cooperation and Development (OECD). 2011. Towards Green Growth. Paris: OECD.

55. Oranisation for Economic Cooperation and Development (OECD). 2017. Green Growth Indicators 2017.

56. Pearce. F. 2012. Peak planet: are we starting to consume less? New Scientist 214, 38-43.

57. Polimeni, J. M., Mayumi, K., Giampietro, M., and Alcott, B. 2008. The Jevons Paradox and the Myth of Resource Efficiency Improvements. London: Earthscan.

58. Rockström, J. et al. 2009. Planetary boundaries: exploring the safe operating space for humanity. Ecology and Society 14, no. 2.

59. Sagoff, M. 2008. 'On the Economic Value of Ecosystem Services'. Environmental Values 17(2): 239-57.

60. Schandl, H., et al. 2016. Decoupling global environmental pressure and economic growth: Scenarios for energy use, materials use and carbon emissions. Journal of Cleaner Production 132 (2016): 45-56.

61. Schroder, E., and Storm, S. 2018. Economic growth and carbon emissions: The road to 'hothouse Earth' is paved with good intentions. Institute for New Economic Thinking, Working Paper 84.

62. Smith, P., Davis, S.J., Creutzig, F., Fuss, S., Minx, J., Gabrielle, B., Kato, E., Jackson, R.B., Cowie, A., Kriegler, E. and Van Vuuren, D.P. 2016. Biophysical and economic limits to negative CO2 emissions. Nature Climate Change, 6(1), pp.42-50.

63. Smulders S., Toman M., Withagen, C. 2014. Growth theory and 'green growth', Oxford Rev Econ Pol. 30(3): 423-446. 
64. Solow, RM. 1973. Is the end of the world at hand? Challenge 16, 39-50.

65. Steffen, W., et al. 2015. Planetary boundaries: Guiding human development on a changing planet. Science 347 , no. 6223.

66. Stern, N. 2006. Stern review on the economics of climate change. Cambridge, UK: Cambridge University Press.

67. Turner, A. J., et al. 2016. A large increase in US methane emissions over the past decade inferred from satellite data and surface observations. Geophysical Research Letters 43, no. 5: 2218-2224.

68. United Nations Environment Programme (UNEP). 2011a. Towards a Green Economy: Pathways to Sustainable Development and Poverty Eradication - Full Report (Nairobi: UNEP).

69. United Nations Environment Programme (UNEP). 2011b. Towards a Green Economy: Pathways to Sustainable Development and Poverty Eradication - A Synthesis for Policy Makers (Nairobi: UNEP).

70. United Nations Environment Programme (UNEP). 2011c. Decoupling Natural Resource Use and Environmental Impacts from Economic Growth, Report of the Working Group on Decoupling to the International Resource Panel (Nairobi: UNEP).

71. United Nations Environment Programme (UNEP). 2017a. Assessing Global Resource Use. (Nairobi: UNEP).

72. United Nations Environment Programme (UNEP). 2017b. Resource Efficiency: Potential and Economic Implications. A report from the International Resource Panel.

73. United Nations. 2012. The World We Want.

74. Vaughan, N.E., and Gough, C. 2016. Expert assessment concludes negative emissions scenarios may not deliver. Environmental Research Letters 11.

75. Van Vuuren, D.P. et al. 2011. RCP2. 6: exploring the possibility to keep global mean temperature increase below 2 C. Climatic Change 109, no. 1-2: 95-116.

76. Van Vuuren, D. P. et al. 2017. Open discussion of negative emissions is urgently needed. Nature Energy 2:902-904.

77. Van Vuuren, D.P. et al 2018. Alternative Pathways to the $1.5 \mathrm{C}$ target reduce the need for negative emission technologies. Nature Climate Change 8:391-397.

78. Victor, P. 2008. Managing without growth: slower by design, not disaster. Edward Elgar Publishing. 
79. Voet, E., Oers, L., and Nikolic, I. 2004. Dematerialization: not just a matter of weight. Journal of Industrial Ecology 8, no. 4: 121-137.

80. Wackernagel, M. and Rees, W., 1998. Our ecological footprint: reducing human impact on the earth (No. 9). New Society Publishers.

81. Wanner, T. 2015. The New 'Passive Revolution' of the Green Economy and Growth Discourse: Maintaining the 'Sustainable Development' of Neoliberal Capitalism, New Political Economy 20:1, 21-41.

82. Ward, J.D. et al. 2016. Is decoupling GDP growth from environmental impact possible? PloS one 11, no. 10.

83. Weizsäcker, E.U., Lovins, A.B., Lovins, L.H. 1998. Factor Four: Doubling Wealth, Halving Resource Use. Club of Rome. Earthscan, London.

84. Wiedmann, T. O., et al. 2015. The material footprint of nations. Proceedings of the National Academy of Sciences 112, no. 20: 6271-6276.

85. World Bank. 2012. Inclusive Green Growth: The Pathway to Sustainable Development Washington, DC: World Bank.

\footnotetext{
${ }^{1}$ Steffen et al (2015) have identified biosphere integrity and climate change as the core planetary boundaries meriting most concern.

${ }^{2}$ Wiedmann et al (2015) come up with a similar figure, 70 billion metric tons in 2008.

${ }^{3}$ This trend was driven primarily by growth in industrial and construction materials, primarily in Asia. It is not clear, however, how much of this material use has been consumed domestically and how much has been exported for consumption abroad.

${ }^{4}$ The UNEP model suggests that decoupling can be achieved at a max rate of $1 \%$ per year. Therefore GDP growth would have to be less than $1 \%$ per year in order for resource use to be reduced.

${ }^{5}$ Even while $\mathrm{CO} 2$ emissions had plateaued, methane emissions were growing, by more than $30 \%$ between 2002 and 2014 (Turner et al 2016).

${ }^{6}$ The trend looks somewhat more promising if we use PPP dollars instead of constant USD, but PPP calculations are unreliable and tend to overstate the purchasing power of poor countries.

7 'Climate Scoreboard', Climate Interactive.

${ }^{8}$ Another 9 scenarios include some BECCS, but not to the point of achieving negative emissions.

${ }^{9}$ PWC Low Carbon Economy Index 2017

$10150 \mathrm{GW}$ were installed in 2017; the IRENA scenario requires that $350 \mathrm{GW}$ be installed per year on average to 2050. This is feasible with existing growth rates (from 2016-2018 solar and wind capacity grew by $8 \%$ per year), but IRENA do not specify the trajectory necessary for 2C. Jacobson and Delucchi (2011) indicate that $700 \mathrm{GW}$ need to be added per year to $2030-4.6$ times the existing rate. This requires a growth rate of $25 \%$ per year on existing rates.

${ }^{11}$ Global energy intensity improved by $1.3 \%$ per year from 2000-2010, and 1.8\% per year from 2010-2015.

${ }^{12}$ Jacobson and Delucchi (2011) claim that global energy demand will decline by $36 \%$ (relative to business as usual by 2050) as fossil fuels are replaced by wind and solar, which means that demand in 2050 will be less than demand in 2012.

${ }^{13}$ Using the equation: Rate of necessary decoupling = GDP growth rate / ( 1 - Rate of necessary emissions reductions).

${ }^{14}$ Decoupling slowed from an average of $2.3 \%$ per year in the first half of the period to an average of $1.6 \%$ in the second half, according to the World Bank, Databank, CO2 emissions (kg per 2010 US\$ GDP).
} 
${ }^{15}$ Personal correspondence, 2018. Also, it is worth noting that Grubler et al state that LED does not incorporate rebound effects; they acknowledge that this is a relevant shortcoming of the work.

${ }^{16}$ For a detailed discussion of this question, see Ekins 2012. 